ZOOLOGIA 27 (3): 451-454, June, 2010

doi: $10.1590 /$ S1984-46702010000300019

\title{
A new species of Tormopsolus (Digenea: Acanthocolpidae) parasite of Genypterus brasiliensis (Teleostei: Ophidiidae) from the Brazilian coast
}

\author{
Marcelo Knoff ${ }^{1} \&$ Berenice M. M. Fernandes²
}

\author{
${ }^{1}$ Laboratório de Helmintos Parasitos de Vertebrados, Instituto Oswaldo Cruz. Avenida Brasil 4365, 21045-900 Rio de \\ Janeiro, Rio de Janeiro, Brazil. E-mail: knoffm@ioc.fiocruz.br \\ ${ }^{2}$ Laboratório de Helmintos Parasitos de Peixes, Instituto Oswaldo Cruz. Avenida Brasil 4365, 21045-900 Rio de Janeiro, \\ Rio de Janeiro, Brazil. E-mail: berenice@ioc.fiocruz.br
}

\begin{abstract}
Tormopsolus brasiliensis sp. nov. is described from the intestine of Genypterus brasiliensis Regan, 1903, from Brazil. The new species is characterized mainly by having an almost square terminal oral sucker, a pharynx of the same size or larger than the oral sucker, and testes very close to each other and without vitelline follicles between them. Tormopsolus brasiliensis sp. nov. is most closely related to T. lintoni Caballero, 1952, sharing with the latter the space between the gonads and the distribution of the vitelline fields. It differs from that species by the lack of a space between the gonads and the absence of vitelline follicles between the testes; by the smaller distance between the oral and ventral suckers; by the presence of a wide ejaculatory duct armed with spines; a wide metraterm, almost the same size of the cirrus-sac; and by the shape and terminal position of the oral sucker. Specimens recovered already dead showed distinct differences to the well-fixed, freshly-collected material and are these differences are enumerated. Acanthocolpus brasiliensis of Alves et al. (2002a,b) is considered synonym of $T$. brasiliensis sp. nov.
\end{abstract}

KEY WORDS. Marine fish; South America; taxonomy; Tormopsolus brasiliensis sp. nov.; Trematoda.

During studies of the helminthofauna of marine fishes from the coast of Rio de Janeiro State, Brazil, 38 specimens of Genypterus brasiliensis Regan, 1903 (Ophidiidae) were examined. Digenean parasites, corresponding to as a new species of Tormopsolus Poche, 1926, were found in the intestine of twenty of them.

According to Froese \& PAULY (2008) G. brasiliensis occurs in the subtropical waters of the Southwest Atlantic Ocean, in depths that range $60-200 \mathrm{~m}$.

Species belonging to Tormopsolus have been described from the Adriatic Sea, the Mediterranean Sea, the Southwestern coast of Australia, the North Atlantic Ocean, the Arabian Sea, the Indian Ocean, the South China Sea, the Red Sea and the North Pacific Ocean. Bray \& CRibb (2001) described a new species, $T$. attenuatus, and presented a cladistic analysis of the genus using 31 morphological and metrical characters. The authors considered Tormopsolus as including 11 valid species. BARTOLI et al. (2004) redescribed T. orientalis Yamaguti, 1934 based on specimens from the western Mediterranean Sea and studied specimens of T. medius Reimer, 1983 from Mozambique, considering it a synonym of T. orientalis. They recognized only 10 species for Tormopsolus. More recently, three records of Tormoposolus sp. have been published; one by EL-Labadi et al. (2006), for specimens recovered from Dactyloptena peterseni (Nyström, 1887), Parupeneus macronemus (Lacepède, 1801) and Priacanthus hamrur (Forsskål, 1775) from the Red Sea; one by Songsuk \& PURIVIrojKul (2007), for specimens recovered from Nemipterus hexodon (Quoy \& Gaimard, 1824), from the Gulf of Thailand; and one by PérezDel Olmo et al. (2008) for metacercariae recovered from Boops boops. In the present paper we propose T. brasiliensis sp. nov., a parasite of G. brasiliensis from Brazil, representing the first record of this genus in South America.

\section{MATERIAL AND METHODS}

Between October 2002 and September 200338 specimens of $G$. brasiliensis, $54.5-93.0 \mathrm{~cm}$ total length, were examined. Specimens were purchased in fish markets in the municipalities of Niterói and Rio de Janeiro, state of Rio de Janeiro, Brazil. After collection, the fish were transported in an insulated box filled with ice to the Laboratório de Helmintos Parasitos de Vertebrados do Instituto Oswaldo Cruz (IOC), Fundação Oswaldo Cruz (FIOCRUZ), Rio de Janeiro, where they were identified according to Figueiredo \& Menezes (1978). Specimens were subsequently necropsied and their organs were analyzed. The internal organs were transferred to the Petri dishes with a saline solution at $0.65 \% \mathrm{NaCl}$ and observed through the stereomicroscope. The digeneans collected from the intestine were cold fixed in AFA, without compression, stained with Langeron's alcoholic acid carmine, dehydrated in an ethyl alcohol series, cleared in beechwood creosote and finally mounted in Canada balsam as permanent slides. The taxonomic classification is in 
accordance with Bray (2005). The whole mounts were observed at the Olympus BX 41 bright field microscope and measured. Measurements, unless otherwise stated, are given in micrometers, and quoted as a range with their means between parentheses. Figures were drawn with the aid of a drawing tube. Photographies were taken using a Zeiss Axiophot bright field microscope. Parasite indexes follow the concepts of BusH et al. (1997). Specimens studied are deposited in the "Coleção Helmintológica do Instituto Oswaldo Cruz" (CHIOC), Brazil.

\section{TAXONOMY}

\section{Tormopsolus brasiliensis sp. nov.} Figs 1-4

Description: based on 16 adult specimens. Body elongate, tapering posteriorly, 2.62-6.32 $\mathrm{mm}(4.04 \mathrm{~mm})$ long, $\mathrm{n}=$ 16 , by $0.45-0.97 \mathrm{~mm}(0.66 \mathrm{~mm})$ wide, $\mathrm{n}=16$, widest at the level of ventral sucker or ovary. Tegument spinous; spines denser at anterior third of body, decreasing at level of ovary. Spines not visible in most specimens. Oral sucker almost square, terminal, wider than long, measuring 170-310 (210) long, $\mathrm{n}=16$ by $150-350$ (259) wide, $\mathrm{n}=16$. Ventral sucker round, protuberant, preequatorial, larger than oral sucker, 300-650 (453) long, $\mathrm{n}=16$, by 280-570 (457) wide, $\mathrm{n}=16$. Sucker width ratio 1:1.62 (1.8), $\mathrm{n}=16$. Length between ventral sucker and ovary 3502,150 (442). Prepharynx long, 100-360 (209), $n=16$. Pharynx well developed, subequal in to, or larger than, oral sucker, 170389 (286) long, $\mathrm{n}=16$, by 170-400 (306) wide, $\mathrm{n}=16$. Oral sucker/pharynx width ratio 1:07-1.3 (1.0), $\mathrm{n}=16$. Esophagus apparently absent or short, 100-170 (133) long, $n=3$, bifurcating at level of anterior margin of ventral sucker. Caeca wide, reaching posterior extremity, uroproct present, sometimes inconspicuous due to a large number of vitelline follicles. Testes two, round to oval, entire, median, tandem, not separated from each other by vitelline follicles, situated at posterior third of body, close to posterior extremity. Anterior testis 260-700 (435) long by 180-460 (369) wide, $\mathrm{n}=16$, posterior testis $300-700$ (470) long by 200-490 (379) wide, $\mathrm{n}=16$. Cirrus-sac elongate $730-2,150(1,342)$ long by 130-275 (180) wide, $\mathrm{n}=10$, containing entire saccular elongated internal seminal vesicle, 350-1,000 (654) long by 100-220 (150) wide, $\mathrm{n}=10$, pars prostatica tubular, 200-720 (380) long by 50-90 (66) wide, $\mathrm{n}=5$, and ejaculatory duct wide and armed with spines, 250-580 (380) long by 60-220 (170) wide, $\mathrm{n}=7$. Genital pore between pharynx and ventral sucker, the latter very closer to each other. Ovary round, entire, 160-400 (235) long by 130-330 (235) wide, $\mathrm{n}=13$, immediately anterior to anterior testis, vitelline follicle between ovary and testis generally absent, (in two specimens, the ovary is very close to anterior testis, 2-3 vitelline follicles between them). Uterine seminal receptacle pre-ovarian. Mehlis's gland present, Laurer's canal inconspicuous. Uterus pre-ovarian, intercaecal. Metraterm wide, longer than ejaculatory duct, almost the same length as cirrus-sac, with thin walls, without spines $520-1,000$ (782) long by 80-360 (232) wide, $\mathrm{n}=8$. Eggs operculated, mostly collapsed, 40-90 (70) long by 25-50 wide (35), $\mathrm{n}=49$, and uncollapsed, 60-85 (72) long by 35-60 (43) wide, $n=24$. Vitellarium follicular; extending from posterior half of seminal vesicle to posterior extremity of body, not interrupted, overlapping ovary and testes; in some specimens vitelline follicles reach posterior margin of ventral sucker. Excretory vesicle inconspicuos. Excretory pore terminal.

\section{Taxonomic summary}

Synonym: Acanthocolpus brasiliensis of Alves et al. (2002a,b).

Type host: Genypterus brasiliensis Regan, 1903, Ophidiidae, "congro-rosa".

Site of infection: intestine.

Type locality: Niterói $\left(43^{\circ} 06^{\prime} 13^{\prime \prime} \mathrm{W}\right.$ and $\left.22^{\circ} 53^{\prime} 00^{\prime \prime} \mathrm{S}\right)$, Rio de Janeiro State, Brazil.

Other locality: Rio de Janeiro $\left(43^{\circ} 12^{\prime} 27^{\prime \prime} \mathrm{W}\right.$ and $22^{\circ} 54^{\prime}$

10 " S), Rio de Janeiro State, Brazil.

Prevalence: $52.6 \%$ (20 of 38 fish examined).

Range of intensity: 1-146 per infected fish.

Mean intensity: 40.6 (812 parasites per 20 infected fish). Mean abundance: 21.4 (812 parasites per 38 fish examined). Brazil.

Etymology: the specific name refers to the type locality,

Specimens examined: CHIOC ns. 30928a (holotype), b-f (paratypes) of Pseudolepidapedon brasiliensis (Fernandes \& Souza, 1973) Ramadan, 1987 and CHIOC n. 34569 (voucher) of Acanthocolpus brasiliensis of Alves et al. (2002a).

Type specimens: holotype CHIOC number 37.228a (type); paratypes 37.228b-1, 37.229, 37.230, 37.231a-b.

\section{DISCUSSION}

The main morphological characters of the new species are as follows: the almost square terminal oral sucker; the pharynx subequal in size to or larger than the oral sucker; and gonads very close to each other, without vitelline follicles between them. None of the previously described species of Tormopsolus have an almost square terminal oral sucker. In combination, the characters mentioned above are sufficient to differentiate the new species from all other species of the genus. Those (10) species have vitelline follicles between the gonads, and the fields may interrupted or not at the level of the ovary and testes (Bray \& Cribb 2001, El-Labadi et al. 2006).

Tormopsolus brasiliensis sp. nov. is most closely related to T. lintoni Caballero, 1952, described from the intestine of Enchelyopus cimbrius (Linnaeus, 1766), from Massachusetts, USA. It differs from that species by the following features: the lack of a space and vitelline follicles between the testes; the smaller distance between the oral and ventral suckers; the presence of a wide ejaculatory duct armed with spines; a wide metraterm that is longer than the ejaculatory duct and almost 

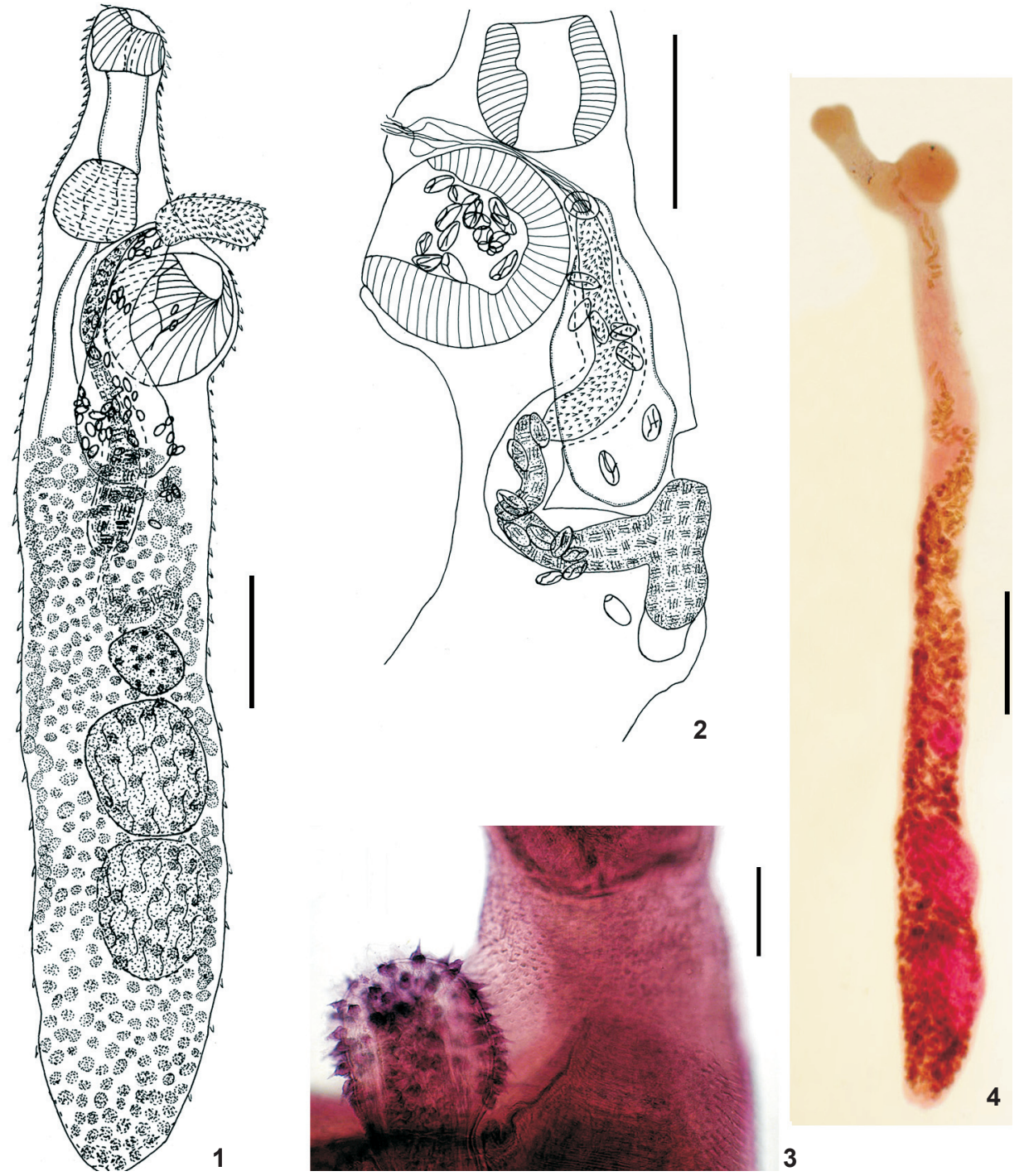

Figures 1-4 Tormopsolus brasiliensis sp. nov.: (1) total, lateral view; (2) detail of terminal genitalia, ventral view; (3) light micrograph of the terminal genitalia; (4) total of a specimen with alterations. Scale bars: $1,4=500 \mu \mathrm{m}, 2=400 \mu \mathrm{m}, 3=100 \mu \mathrm{m}$.

the same length as the cirrus-sac; and the shape and terminal position of oral sucker.

Mostly, the specimens that were recovered already dead showed distinct differences when compared with the well-fixed, freshly-collected material. Specimens of the first are very long and narrow, with fewer spines on the tegument and in the ejaculatory duct, and a greater distance between the ventral sucker and the ovary and between the ovary and the anterior testis. Main measurements based on seven specimens: Body 2.95-4.67 (3.62) x 0.12-0.27 mm (0.19 mm); oral sucker 110-165 (146) x 155-190 (172); ventral sucker 200-270 (235) x 215-260 (234); sucker width ratio 1: 1.3-1.5 (1:1.4); length between ventral sucker and ovary 1,375-2,270 $(1,916)$; prepharynx 115-210 (160); pharynx 105-170 (140) x 105-145 (127); anterior testis 210-475 (339) x 155-280 (196); posterior testis 235-580 (372) x 150-250 (186); ovary 110-105 (170) x 70-165 (123); collapsed eggs 62-77 x 27-37 (75 x 34), uncollapsed 75-80 x 37-42.

In South America two other digeneans has been reported from G. brasiliensis: Lecithochirium genypteri Lühe, 1901, mentioned by Sardella et al. (1998) from Argentina, and Pseudolepidapedon brasiliensis referred to as Acanthocolpus brasiliensis Fernandes \& Souza, 1973 by Alves et al. $(2002 a, b)$ from Brazil. Alves et al. (2002a,b) reported A. brasiliensis parasitizing the intestine of $G$. brasiliensis also from the shores in Rio de Janeiro 
State. We had the opportunity to study a specimen previously analyzed by Alves et al. $(2002 \mathrm{a}, \mathrm{b})$ deposited in the CHIOC $\mathrm{n}$. 34569 and have verified that it is similar to those specimens that had been collected already dead (see above). Based on this similarity, we have concluded that it belongs to our new species and we consider it a synonym of T. brasiliensis sp. nov.

\section{ACKNOWLEDGEMENTS}

Thanks to Rodrigo do E.S. Padovani, fellow of the Fundação de Amparo a Pesquisa do Estado do Rio de Janeiro (FAPERJ), for technical assistance during the necropsies, and to Heloisa M.N. Diniz from the Serviço de Produção e Tratamento de Imagens, IOC, FIOCRUZ, for the assistance in the preparation of the plate.

\section{LITERATURE CITED}

Alves, D.R.; J.L. Luque \& A.R. Paraguassú. 2002a. Metazoan parasites of pink cusk-eel, Genypterus brasiliensis Regan, 1903 (Osteichthyes, Ophidiidae) from the coastal zone of the state of Rio de Janeiro, Brazil. Revista Brasileira de Zoociências 4 (1): 133-142.

Alves, D.R.; J.L. Luque \& A.R. Paraguassú. 2002b. Community ecology of the metazoan parasites of pink cusk-eel, Genypterus brasiliensis (Osteichthyes: Ophidiidae), from the coastal zone of the State of Rio de Janeiro, Brazil. Memórias do Instituto Oswaldo Cruz 97 (5): 683-689.

Bartoli, P.; R.A. Bray \& F.E. Montero. 2004. Tormopsolus orientalis Yamaguti, 1934 (Digenea: Acanthocolpidae) from Seriola dumerili (Risso) (Perciformes: Carangidae) in the western Mediterranean Sea. Systematic Parasitology 57 (3): 201-209.

BraY, R.A. 2005. Family Acanthocolpidae Lühe, 1906, p. 603619. In: A. Jones; R.A. Bray \& D.I. Gibson (Eds). Keys to the
Trematoda. London, CAB International and Natural History Museum, vol. 2, XVI+745p.

BraY; R.A. \& T.H. Cribb. 2001. Tormopsolus attenuatus n. sp. (Digenea: Acanthocolpidae) from Seriola hippos (Perciformes: Carangidae), Western Australia, with some observations on the relationships in the genus. Systematic Parasitology 50 (2): 91-99.

Bush, A.O.; K.D. Lafferty; J.M. Lotz \& A.W. Shostak. 1997. Parasitology meets ecology on its own terms: Margolis et al. revisited. Journal of Parasitology 83 (4): 575-583.

EL-LABADI, S.N.; N.S. IsMAIL \& M. KHALAF. 2006. Intestinal digenetic trematodes of some fishes from the Gulf of Aqaba, Red Sea. Pakistan Journal of Zoology 38 (4): 43-48.

Fernandes, B.M.M. \& S.V. Souza. 1973. Sobre uma nova espécie do genero Acanthocolpus Lühe, 1906. Memórias do Instituto Oswaldo Cruz 71 (3): 241-245.

Figueiredo, J.L. \& N.A. Menezes. 1978. Manual de peixes marinhos do Sudeste do Brasil. II. Teleostei (1). São Paulo, Museu de Zoologia, Universidade de São Paulo, 110p.

Froese, R. \& D. Pauly. 2008. FishBase. Available online at: http:/ /www.fishbase.org [Accessed: 10/X/2008].

Pérez-del Olmo, A.; M. Fernández; J.A. Raga; A. Kostadinova \& R. Poulin. 2008. Halfway up the trophic chain: development of parasite communities in the sparid fis Boops boops. Parasitology 135: 257-268.

Sardella, N.H.; M.F. Avendaño \& J.T. Timi. 1998. Parasites communities of Genypterus blacodes and G. brasiliensis (Pisces: Ophidiidae) from Argentina. Helminthologia 35 (4): 209218.

Songsuk, A. \& W. Purivirojkul. 2007. Parasites of Pla Sai Dang Nemipterus hexodon (Quoy \& Gaimard) from gulf of Thailand in Chonburi province area. Proceedings of the 45th Kasetsart University Annual Conference, Kasetsart: 415-423.

Submitted: 29.VII.2009; Accepted: 25.III.2010.

Editorial responsibility: Marcus V. Domingues 